\title{
CORRECTION
}

\section{Correction to: Molecular mapping of dominant gene responsible for leaf curl virus resistance in chilli pepper (Capsicum annuum L.)}

\author{
Hament Thakur $^{1} \cdot$ Salesh Kumar Jindal ${ }^{1} \cdot$ Abhishek Sharma $^{1} \cdot$ Major Singh Dhaliwal $^{1}$
}

Published online: 4 September 2020

(c) King Abdulaziz City for Science and Technology 2020

\section{Correction to: 3 Biotech (2020) 10:182}

https://doi.org/10.1007/s13205-020-02168-7

Unfortunately, the article has been published with an error in the sequence of marker CA 516044 in the manuscript in Table 1 and Supplementary File. The table with correct sequence is given below:

Old sequence:

\begin{tabular}{llll}
\hline & Primer name & Forward & Reverse \\
\hline 1 & CA 516044 & ATTTTCTTTTCA & T GCTCAGCATTAA \\
& & TTTCCCCCTTT & CGACGTC \\
\hline
\end{tabular}

Correct sequence:

\begin{tabular}{llll}
\hline & Primer Name & Forward & Reverse \\
\hline 1 & CA 516044 & ATCTTCTTCTCA & T GCTCAGCATTAA \\
& & TTTCTCCCTTC & CGACGTC \\
\hline
\end{tabular}

The original article can be found online at https://doi.org/10.1007/ s13205-020-02168-7.

Hament Thakur

hemantt114@gmail.com

1 Department of Vegetable Science, Punjab Agricultural

University, Ludhiana 141004, India 